\title{
E-Measures: a comprehensive waste of time?
}

Stephen Town, Cranfield University.

\section{Introduction \& Structure}

Measurement changes the world; it is not a neutral activity.

What we decide to measure in the library e-environment will result in adaptation of our behaviour to maximise the chosen measures. In so doing it will help define what future libraries are, what they do, and demonstrate their priorities. Research and development of e-measures and datasets should therefore proceed from a full and clear analysis of what the future library is expected to be and to do.

The title of this paper is of course provocative. Librarians tend to select the batteries of indicators approach to performance measurement as a first resort. The emphasis on comprehensiveness of data sets chosen on the basis of availability rather than thought and at the expense of comprehension of what constitutes performance is a wellestablished tradition. Measurement is not performance, and may inhibit it (Town, 1997).

This paper does not seek to be a criticism of any particular existing programme to define e-measures, e-metrics, or e-library and e-resource performance measures, evaluation, indicators, statistics or datasets. The first term will be used throughout this paper to encompass all these terminological variants. The paper also does not seek to provoke an argument over the respective values of quantitative and qualitative data. It is a plea for balance, and for broader and deeper thought before the commitment of large-scale effort to data collection. Otherwise e-measures collection may be a 'waste of time'. Although measurement might be easier to achieve in the e-environment there is no excuse for repeating past mistakes. 
Van House pointed out very early in the history of digital library performance measurement that understanding and measuring use cannot be separated from an understanding of the context in which people work (Van House, 1995). More recently Boyle criticised much public data collection for its 'pervasive blindness' which results from the inability to see the complex truths beyond the figures (Boyle, 2000). Boyle quotes a film script to ask 'why are boys obsessed with numbers?', and there may be an element of this influence in the size and numbers obsession in library performance measurement (Town, 2002).

The quality management movement reinforces these arguments. Deming suggested that one of the diseases of western industry was 'management by use only of visible figures' and argues for measures which provide the full picture of performance, including customer satisfaction, employee morale, and community impact (Deming, 1986). These dimensions are still underrepresented in academic library data collection efforts.

Consequently this paper is intended to encourage a broader perspective on emeasurement and evaluation, and is organised as follows:

- A critique of current concepts

- Four potential routes for a better understanding of measurement dimensions

- A possible outline framework for e-measures through the balanced scorecard approach

\section{Critique}

A number of questions arise around the collection of e-measures datasets. The first is why the enterprise seems to be a separate consideration from the hybrid reality in which we operate? Few if any academic libraries are e-only, and datasets should surely integrate with existing measurement and evaluation frameworks. 
Secondly, are there influences on the construction of the datasets which might distort selection or priorities? E-measures data collection is certainly a bandwagon issue. Because e-measures relate to technology and to the use of expensive resources it is perhaps easier to source funds for research which relate directly and obviously to the technology and to those resources. Thus the associated vested interests influence the datasets towards inputs and access rather than towards outputs and outcomes.

Thirdly, why is there now such a focus on usage data, particularly when little or no effort was made to assess use of the equivalent print serials collections in the past? This may of course be because selection of serials has little to do with use, or value for money, and much more to do with the core journals in which academic staff publish or aspire to publish. It may be that the core journals will change in the eenvironment, or be replaced by other publishing routes, but this will not be recognised through usage data alone.

Fourthly, usage data appears to be taken to indicate use, and to be used for evaluation in a way that assumes all usage is useful use. This seems a questionable assumption, given that what is being recorded is access rather than use. This may be positively dangerous if used to inform selection decisions or impute comparative value of resources. Such decisions require understanding of the context of use and a more definitive statement of value from the user. Counting is still no substitute for listening.

\section{Sources and routes}

The above arguments imply that the broader context might be worth considering in our pursuit of useful e-measures. Four sources for informing the concept and subsequent choice of e-measures are presented below:

1. Scholarly communication and the 'Journal Flow Model'

2. Information literacy.

3. Developments in measuring e-resource and e-service quality.

4. Library serials management issues.

\section{The Journal Flow Model}


The quest for e-measurement systems (and indeed our approach to operating libraries) should be based on a firm understanding of scholarly communication in the new environment.

\section{Figure 1}

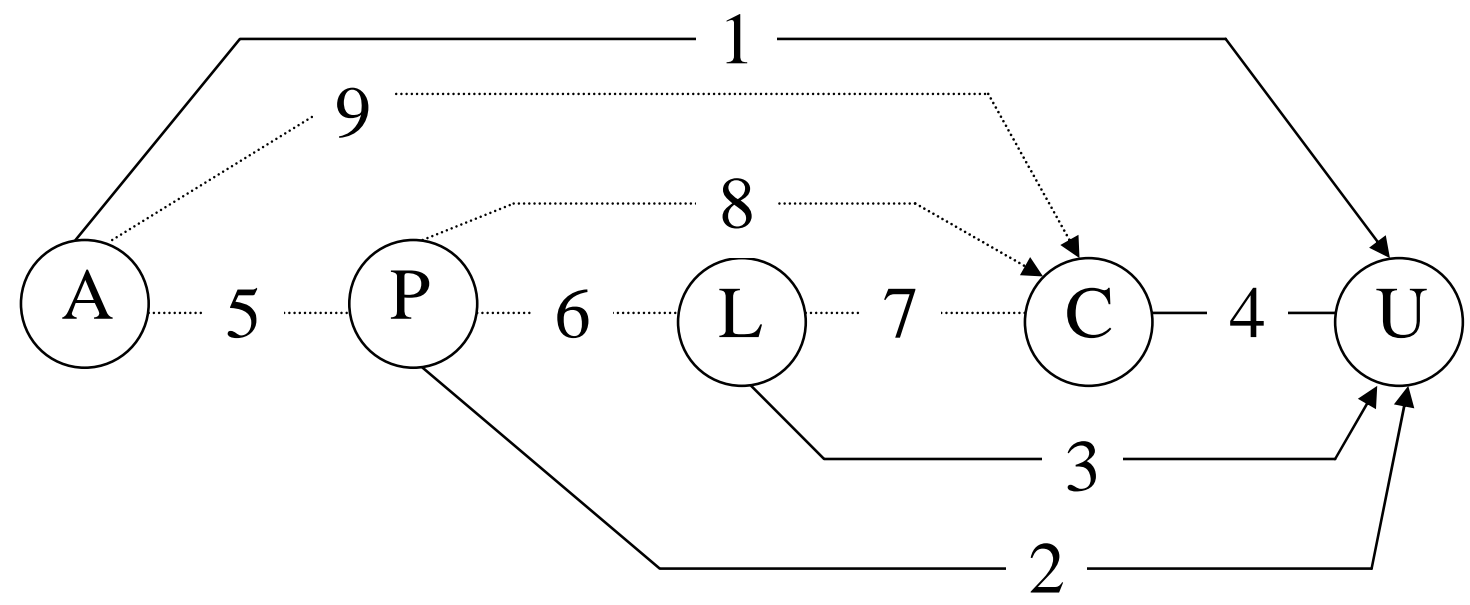

Nearly thirty years ago King and others (King, 1976) defined a journal flow model which identified nine routes for the dissemination of scientific information (see Figure 1). These are listed below:

1. Author and user

2. Publisher and user

3. Library and user

4. Colleague and user

5. Author and publisher

6. Publisher and library

7-9. Colleague routes

The issue for libraries is that currently e-resources are mainly delivered through route 2 rather than route 3 . In counting usage therefore it could be argued that the counts are related to a process to which we now add little value, except in a financial managerial sense. 
In this digital era it will be important to research and reconstruct the model to take into account the new realities and proportions of flow in all potential dissemination routes. How are routes 2 and 4 operating in the e-environment? Does the author's personal web site route for promoting work have any impact on use of e-resources supplied through libraries? The growth of institutional or other repositories may become a major route for communication, and if so how do we determine the value of a resource if we only count its use through the one minor access route which libraries control?

Predictions about future use of electronic libraries have suggested that by 2010 perhaps half the use of library services will be of the dynamic (for example portal and gateway) elements and only $30 \%$ will be use of the digital content. If this prediction holds it suggests that it would be more sensible to ensure that data collection was focussed on the elements where we do add value (the portals and gateways), rather than focussing on counts based on content or traditional routes of access.

Conclusions from this section therefore might be summarised in a number of questions that need to be applied to our e-measure datasets:

- Are we interested in measuring all use? If so we need a model for other routes and mechanisms for capturing data in relation to each route.

- Are we missing significant use? Clearly we may be and the potential for doing so increases with the growth of collective repositories.

- Are we failing to count local repository use? By missing this element of use we will be evaluating other resources on a false premise.

- Are we missing VLE-related use? It would seem reasonable to count use of embedded resources in a way that differentiates them from other counts, as we are adding significant value in the embedding.

- Are we counting the wrong things all together? If most future use is of the value added portal elements of our services we need to count that use and accord it greater priority in our data collection efforts. 


\section{Information Literacy}

Take up and use of e-services is completely dependent on the knowledge and abilities of users. The information literacy or e-literacy dimension of e-services is therefore one that underpins and informs all other e-measures. Put simply, if much use is misuse, and all usage figures are fundamentally dependent on user capability, then the data is worthless unless this aspect of the context is understood. Evidence suggests that user knowledge and abilities in relation to e-resources may be lacking at all levels (Armstrong, 2001), even amongst those who might be expected to have a key role in encouraging use of e-resources (Hunn, 2003).

User competence is now well-defined for UK higher education users of e-resources through the SCONUL Seven Pillars Model (Town, 2000). This defines a set of headline information skills (although 'skills' may now be considered too narrow a term) which a competent user might be expected to have:

1. Recognise information need

2. Distinguish ways of addressing gap

3. Construct strategies for locating

4. Locate and access

5. Compare and evaluate

6. Organise, apply and communicate

7. Synthesis and create

An effective e-measures framework ideally needs to contain data elements for these skills to set against usage of resources within a particular user segment. Clearly this takes the measurement requirement outside the traditional library measurement envelope into the broader academic domain.

A series of workshops supported by SCONUL's Advisory Committee on Performance Improvement and its Information Skills Task Force resulted in the identification of potential measurement dimensions for information literacy institutional programmes, together with lists of suggested measures (Town, 2003). The resulting framework suggested these key dimensions to be: 
- Library staff related measures

- Resource measures

- Student outcome measures

- Partnership measures

- Strategic framework measures

- Pedagogic quality measures

Impact measures relating to information literacy are the subject of a number of the institutional projects within the SCONUL/LIRG Impact Measures programme currently in progress (Conyers et al, 2003). Such outcome measures will be a key component of an effective e-measurement framework.

\section{LibQUAL+ and e-QUAL}

Customer satisfaction data will be an essential element of any effective e-measures framework. LibQUAL+ is a potential source of this data. LibQUAL+ is a survey instrument developed from the SERVQUAL methodology and offered now internationally by the Association of Research Libraries (ARL). The survey instrument is comprised of questions which require users to define their minimum, perceived and desired expectation of an element of library service (Association of Research Libraries, 2004). Currently twenty-two questions are grouped into three dimensions of service quality: information control, affect of service, and library as place. The first dimension may be the most obvious source of data in relation to eresources, offering the following specific questions:

- Making electronic resources accessible from my home or office

- A library Web site enabling me to locate information on my own

- The printed library materials I need for my work

- The electronic information resources I need

- Modern equipment that lets me easily access needed information

- Easy-to-use access tools that allow me to find things on my own

- Making information easily accessible for independent use 
- Print and/or electronic journal collections I require for my work

Although LibQUAL + is a general market survey, the ability to analyse the data by level of user and subject affiliation can provide insight into the precise satisfaction levels of market groups and identify areas where there may be dissatisfaction with eresources. When combined with usage data this can present a fuller picture for eresource evaluation. LibQUAL+ also offers the ability to add up to five specific questions from a large additional bank, but perhaps more importantly provides the opportunity for users to enter free text comments on any aspect of the service they choose. This can provide additional qualitative data on e-resource performance. Almost one-fifth of the free text comments received by one participating institution in the 2003 SCONUL LibQUAL+ cohort related to e-resources or their delivery.

It has been recognised by those working in the field of customer satisfaction that a new conceptual analysis of service dimensions is required for the e-environment. Parasuraman and others, who originated SERVQUAL, have begun to define these dimensions within a conceptual framework based on findings from users of companies that deliver products and services via the web (Zeithaml et al, 2000). It is impossible here to give full justice to this work, but the analysis attempts to identify both potential service gaps in the e-environment and a set of dimensions of service.

E-service performance is described as a means-end chain, in which the physical and perceptual attributes of a service site lead to perceptions of service quality. The potential dimensions of 'e-quality' identified in this context include:

- Access

- Ease of Navigation

- Efficiency

- Flexibility

- Reliability

- Personalisation

- Security/Privacy

- Responsiveness 
- Assurance/Trust

- Site Aesthetics

- Price Knowledge

ARL are now applying this research to the digital library environment, with the intention of creating an 'e-QUAL' instrument (Blixrud et al, 2003).

The conclusions from this section are that satisfaction and experience measures will be a vital part of any e-measurement or evaluation framework. This may require a change of perception; libraries need to recognise themselves as e-service providers, to understand fully the processes this encompasses, and to identify the potential service gaps likely to occur in this context. These analyses are a prerequisite for understanding the user experience in the e-environment, and there is a need for defined measures and accompanying instruments for this area of library service.

\section{What's important for serials professionals?}

Management of the e-resource process in libraries is complex. E-measures datasets should support the management challenges by providing information directly related to those areas which are critical to the success of the process, as well as to effective decision-making. If the e-measures frameworks developed do not support these needs fully then they will indeed be a 'waste of time'.

The framework building will benefit from the management experience and understanding of the specialist staff working in the field. At the UKSG Conference four years ago a series of workshops was run to identify critical success factors in eserials management. This in turn should help to define potential performance measures. Those things which are critical to the success of an operation are likely to be the most important things to monitor and measure.

Some of the Critical Success Factors sets developed in these workshops are shown below: 
We need:

- to arrange timely access to relevant serials content in an appropriate medium

- to publicise what's available and where it might be obtained

- the right staff structure

- the right environment

- the right budget

We need:

- early knowledge of budget

- well-trained adaptable staff with good management to sell the vision

- acquire the right information

- good two way communication with users and good PR

- selection and evaluation of suppliers

- physical environment

- a plan

We need:

- to identify the stuff the user wants

- $\quad$ sufficient funds

- the necessary infrastructure

- to educate the users

- to get staff to process and deliver

- to identify how and when the user wants the stuff

We need:

- a balanced financial model which is affordable to the user

- a consistent delivery mechanism available to all which supports all media

- $\quad$ to revisit user needs and expectations

- to tell users what is available and consult and optimise

What is interesting from these lists is that usage statistics and basic counts of the kind recommended in e-measures frameworks are not likely to fully answer the needs of those working with the complex reality of e-resource management. Staff and 
relationship issues figure very strongly, whilst finance and use are not often necessarily viewed as connected issues. It is clear from the above that any e-measures framework needs to encompass data and measurement in areas that are difficult and complex if they are to fully serve management need.

\section{A Balanced Scorecard for e-measures}

The Balanced Scorecard approach provides a useful framework for defining a set of measures which are comprehensive enough to guarantee performance and relevant to different stakeholder interests (Kaplan et al, 1996). A set of measures developed on this basis might provide a richer picture of performance, and which should not therefore be 'a waste of time' to develop. The recognition of different stakeholder perceptions is key to this approach, and helps to present the right measures to the right audience.

Applying and developing this framework to the e-measures field might suggest that measures might be developed and categorised under five perspectives:

1. Financial perspective - those measures appropriate for funding stakeholders or financial managers

2. Customer perspective - those measures appropriate and relevant to users interests

3. Process perspective - those measures relating to the management of internal processes associated with e-resources

4. Staff development perspective - those measures relating to the development of individuals capability to work with e-resources

5. Organisational learning and development perspective - those measures relating to the broader organisational capability to manage and deliver eresources

It is not the intention here to define precise measures. This needs to be a local decision based on local requirements. Of course it helps if national, international, and vendor statistical collections are defined in a way that supports local need. The following are some suggestions based on the arguments made above. 


\section{Financial Perspective}

A local market-based approach to financial measurement is likely to be more relevant than an overall attempt at e-resource value-for-money. This latter approach also falls down in the reality of the hybrid situation. In other words a subject-based approach to data covering all resources (e and traditional) is likely to be more relevant and valuable to financial stakeholders.

\section{Customer Perspective}

From a customer perspective totals of usage data may be a waste of time and effort to achieve. Users care about their own usage but they may not be interested in that of others, unless that might affect the availability of the resource. It is probably also clear from the above that satisfaction measures relating to individual e-resources are also not enough to fully reflect this perspective. Satisfaction itself will depend on a range of factors (for example, personal information literacy and the process aspects of the eservice) as well as on the value of the content. Measures therefore which incorporate a deeper understanding of the process aspects of use are needed, and these will highlight the failure gaps. Again in a real life situation hybrid issues and changing expectations need to be reflected in the measurement framework.

\section{Process Perspectives}

Measures in this area need to be based on a full understanding of the processes involved in delivering e-services, and a recognition of the aspects which are critical to the success of the process. It also seems reasonable to concentrate the measurement effort on those areas where the library makes a significant contribution to the value chain. Whilst the business-as-usual aspects of process measurement are covered in analyses of existing chains, the digital environment causes libraries to be constantly engaged in innovation and development projects to bring new services into being. Consequently a project perspective is required alongside the process perspective. This means that project management performance will be critical to e-library success, and consequently related measures will be significant in the e-measurement framework. 
Taking this to the next system level the organisational maturity for achieving multiple and successive quality projects will be important, and at least one institutional Learning Service is beginning to consider measures related to the Capability Maturity Model (CMM) from the software industry to assess its performance in this area (Software Engineering Institute, 2004).

\section{Staff Development Perspective}

Staff may not be seen by some as critical to the delivery of unmediated e-services. In reality the skills, knowledge and understanding required of staff is significantly greater, given the technical, financial and organisational demands. A full framework of e-service related measures will require definition of staff competencies and performance against these, as well as performance of staff against strategic and project targets. Technical and project readiness may require assessment and measurement, and the overall level of a culture of innovation will significantly affect e-service creation and performance, and thus requires measurement tools.

\section{Organisational Learning and Development Perspective}

From an HE organisational perspective the key measures here will relate to impact on learning. The difference e-resources and e-literacy make to learners is the important data to identify here. The performance of e-resources embedded in VLE delivered courses and, probably in the near future, of e-learning objects themselves, and the contribution of both to the success of the overall academic enterprise require associated measures.

\section{Conclusion}

The search for comprehensive e-measures data may be a waste of time if it is not fully informed by an understanding of the real complexity of e-resource use, e-library management, and broader learning outcome issues. As always, listening may be as valuable as counting. A set of e-measures focussed on performance, constructed to 
meet the needs of relevant stakeholders, and developed with a full comprehension of all the processes involved in service delivery is more likely to be successful.

\section{References:}

Armstrong, C. J., Everitt, J., Fenton, R. R., Lonsdale, R. E., McDermott, E. A., Phillips, R., Spink, S., Thomas, R. and Urquhart, C. J. (2001). JUSTEIS JISC Usage Surveys: Trends in Electronic Information Services, Final Report 2000/2001 (Cycle Two) [online]. JUSTEIS Project Board. Available at:

http://www.dil.aber.ac.uk/dils/research/justeis/cyc2rep.pdf [Accessed 17 September 2004].

Association of Research Libraries, (2004). LibQUAL $+{ }^{T M}$ : Defining and Promoting Library Service Quality [online]. Association of Research Libraries. Available at: http://www.libqual.org/About/Information/index.cfm [Accessed 28 July 2004].

Blixrud, J. C. \& Kyrillidou, M. (2003). E-Metrics: Next Steps for Measuring Electronic Resources. ARL Bimonthly Report [online], 230/231, October/December 2003. Available at: http://www.arl.org/newsltr/230/emetrics.html [Accessed 28 July 2004].

Boyle, D. (2000). The Tyranny of Numbers: Why Counting Can't Make Us Happy. London: HarperCollins Publishers.

Conyers, A. and Payne, P. (2004). Making an Impact: the SCONUL / LIRG Measuring Impact Initiative. SCONUL Newsletter. Number 31, Spring 2004. pp. 24 25.

Deming, W. E. (1986). Out of the Crisis: Quality, Productivity and Competitive Position. Cambridge: Cambridge University Press. 
Hunn, R. (2003). An investigation into the level of information literacy of full time research students and academic supervisors at RMCS. MSc Dissertation, University of Bristol.

Kaplan, R. S. \& Norton, D. P. (1996). The balanced scorecard: translating strategy into action. Boston, MA: Harvard Business School Press.

King, D.W., Lancaster, F. W., McDonald, D. D., Roderer, N. K., and Wood, B. L. (1976). Total Cost of Communicating Scientific and Technical Information. Reprinted in Meadows, A. J. (ed) The Scientific Journal: Aslib Reader Series Volume 2. London: Aslib.

Software Engineering Institute, (2004). Capability Maturity Models [online]. Carnegie Mellon University. Available at: http://www.sei.cmu.edu/cmm/cmms/cmms.html [Accessed 28 July 2004]

Town, J. S. (1997). Performance or Measurement. In: Proceedings of the $2^{\text {nd }}$ Northumbria International Conference on Performance Measurement in Libraries and Information Services, Longhirst Management and Training Centre, 7 to 11 September 1997. Newcastle upon Tyne: Information North, pp. 81 - 88.

Town, J. S. (2000). Wisdom of Welfare? The Seven Pillars Model. In: Corrall, S. and Hathaway, H. (eds). Seven Pillars of Wisdom? Good Practice in Information Skills Development: Proceedings of a Conference held at the University of Warwick, 6 to 7 July 2000. London: SCONUL.

Town, J. S. (2002). Seven Toasts for a Summer Evening in Pittsburgh. In: Stein, J., Kyrillidou, M., and Davis, D. (eds). Proceedings of the $4^{\text {th }}$ Northumbria International Conference on Performance Measurement in Libraries and Information Services “Meaningful Measures for Emerging Realities”, Sheraton Station Square Conference Center, Pittsburgh, Pennsylvania, 12 to 16 August 2001. Washington DC: Association of Research Libraries, pp. 357 - 359. 
Town, J. S. (2003). Information Literacy: Definition, Measurement and Impact. In: Martin, A. and Rader, H. (eds). Information and IT Literacy: Enabling Learning in the $21^{\text {st }}$ Century. London: Facet Publishing. pp. $53-65$.

Van House, N. (1995). Organisation Politics and Performance Measurement. In:

Proceedings of the $1^{\text {st }}$ Northumbria International Conference on Performance Measurement in Libraries and Information Services, Longhirst Management and Training Centre, 31 August to 4 September 1995. Newcastle upon Tyne: Information North, pp. $1-10$.

Zeithaml, V. A., Parasuraman, A. \& Malhotra, A. (2000). A Conceptual framework for understanding e-service quality: implications for further research and managerial practice., Cambridge MA: Marketing Science Institute. 
Figure 1

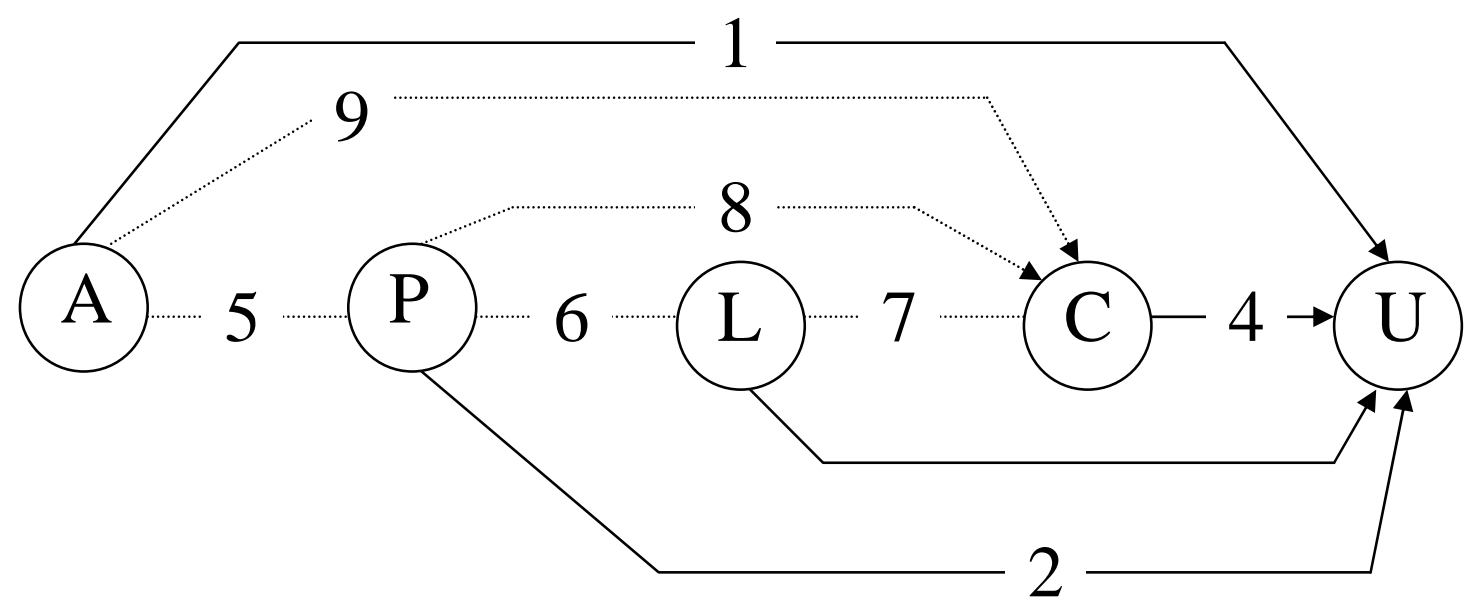

